\title{
GROSS MOTOR FUNCTION CLASSIFICATION SYSTEM (GMFCS) FOR CHILDREN WITH CEREBRAL PALSY
}

\section{Mst. Rabea Begum *1, Mohammad Anwar Hossain ${ }^{2}$, Shahnaj Sultana ${ }^{3}$.}

${ }^{1} \mathrm{MPT}$, MPH (NCD), Senior Clinical Physiotherapist, Physiotherapy Department, Centre for the Rehabilitation of the Paralysed (CRP), Savar, Dhaka, Bangladesh.

${ }^{2}$ MPT, Associate Professor and Head of Physiotherapy Department, CRP, Savar, Dhaka, Bangladesh.

${ }^{3}$ MPT, Assistant Head of Program, CRP, Bangladesh.

\section{ABSTRACT}

Objectives: The objectives were to find out the sociodemographic characteristics, comorbidities, types of CP, level of GMFCS and to determine the association between GMFCS with age, gender, types of CP and topographic distribution among children with cerebral palsy.

Methods and Materials: A retrospectives study was done in children with cerebral palsy. Total 384 participants were included in this study. The study setting was Paediatric Department, Centre for the Rehabilitation of the Paralysed (CRP), Savar, Dhaka, Bangladesh. The samples were collected through convenient sampling. The ChiSquare was used to find out the association between GMFCS with age, gender, types of CP and others.

Results: Males were affected than female among all participants. The majority participants came from rural area. The children were more in 2 to 4 -year age band in GMFCS. The majority participants (81\%) had visual problem, $11 \%$ hearing and $31 \%$ had convulsion. The common levels were II and III. The age bands, topographic classification was associated with GMFCS $(p<0.05)$ but gender and types of CP were not statistically associated $(p>0.05)$.

Conclusion: The Gross Motor Function Classification System (GMFCS) has become an important tool to describe motor function in children with Cerebral Palsy (CP).

KEY WORDS: Gross Motor Function Classification System (GMFCS), Cerebral Palsy.

Address for correspondence: Mst. Rabea Begum, MPT, MPH (NCD), Senior Clinical Physiotherapist, Physiotherapy Department, Centre for the Rehabilitation of the Paralysed (CRP), Savar, Dhaka-1343, Bangladesh, Contact No: +8801675793257.

E-Mail: physio_miilee@yahoo.com,drrabea3@gmail.com

Access this Article online

Quick Response code

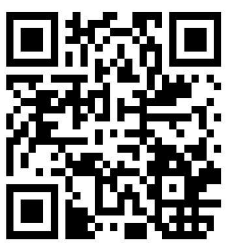

DOI: $10.16965 /$ ijpr.2019.180
Journal Information

International Journal of Physiotherapy and Research ICV for 2016 ISSN (E) 2321-1822 | ISSN (P) 2321-8975 https://www.ijmhr.org/ijpr.html DOI-Prefix: https://dx.doi.org/10.16965/ijpr

\section{Article Information}

Received: 20 Jul 2019

Accepted: 06 Sep 2019

Peer Review: 20 Jul 2019

Published (O): 11 Dec 2019

Revised: None

\section{INTRODUCTION}

Cerebral palsy (CP) is the most frequent cause of motor disability in children and adolescents [1]. CP describes a group of disorders in the development of movement and posture, causing activity limitation which is attributed to non-progressive disturbances that occur in the developing fetal or infant brain. The motor disorders of CP are often accompanied by disturbances of sensation, cognition, communication, perception, and/or behaviour, and/or by a seizure disorder [2]. CP occurs in about 2 to 2.5 per 1,000 live births worldwide and is the most common childhood neuromuscular condition seen by physiotherapists [3].

$\mathrm{CP}$ is classified according to motor type, 
topographical distribution and functional severity level. Recently, there has been increased focus on the functional status of patients, and new classifications for gross motor function is Gross Motor Function Classification System (GMFCS). This classification is widely used to assess the gross motor function in children with CP. The GMFCS is considered to be one of the most important scales for the measurement of function in CP [4].

The GMFCS is a valid and reliable classiûcation instrument which is likely to be reasonably stable over time with or without intervention. The GMFCS has proved to be a valid and reliable too [5]. Functional classification is necessary to recognize the differences in cerebral palsy and to have the best therapeutic planning [6]. The Gross Motor Function Classiûcation System is a standardized method to classify gross motor function in children with cerebral palsy from 0 to 18 years of age. This GMFCS level at age 12 years was highly predictive of adult gross motor function. The validity of the GMFCS for children aged 12 to 18 years has been established, but reliability has not yet been established for this oldest age band. The GMFCS was developed to describe gross motor function in children with $\mathrm{CP}$ and has its focal point on self-initiated movements, in particular sitting and walking. It is an age-related five-level system in which level I represents the least restriction and level $V$ the most. Children with $\mathrm{CP}$ at level I can perform all the activities of their normally developing age-matched peers (although speed and quality of movement may be limited), while children at level $\mathrm{V}$ have difficulty controlling their head and trunk posture in most positions or achieving any voluntary control of movement. GMFCS ratings are prepared on the basis of how old children are with position to four age bands: less than 2 years, from 2 to 4 years, from 4 to 6 years, and from 6 to 12 years. See figure 1. The levels are as follows

Level I: Walks without limitations

Level II: Walks with limitations

Level III: Walks using a hand-held mobility device

Level IV: Self-mobility with limitations; may use powered mobility
Level V: Transported in a manual wheelchair.

The GMFCS has been rapidly accepted into clinical practice and research and has been shown to be directly connected to restrictions in activity and participation [7]. The GMFCS is widely used among healthcare professionals to establish clinical decisions involving future rehabilitation, equipment needs, and functional mobility goals.

Still in Bangladesh there is very few reliable data on this issue and so far, no research findings are available to find out Gross Motor Function Classification System (GMFCS) for cerebral palsy of children. In Bangladesh Centre for the Rehabilitation of the Paralysed is working for disability in all- inclusive approach. CRP Pediatric unit works for the children with disabilities. Among this most of the children are cerebral palsy. In this unit has two ways for treating these children. One is inpatient services and another one is outpatient services. Both services focused therapeutic intervention. Physiotherapy intervention enrich for functional independence for the neurological, orthopaedic conditions etc. Most of them are children with cerebral palsy. After this study therapist will confirm about classification system of gross motor that will supportive for treatment session. So, this study finding may be used to include in assessment for cerebral palsy of children.

The objectives of this study were to assess the distribution of motor impairment with associate disorder, level of gross motor function classification system, sociodemographic characteristics of the participants and to find out the association between age, gender, motor type and topographic classification like hemiplegic, diplegic, quadriplegic etc with GMFCS.

\section{MATERIALS AND METHODS}

A retrospective study was done through convenient sampling procedure. The total 384 samples were selected from population according to sample size estimation. The inclusion criteria constitute as the children age 0 to 12 years, only children with cerebral palsy was recruited. The participants who were unwilling to participate they excluded from this study. The study was approved by ethical committee of Centre for the 
Rehabilitation of the Paralysed (CRP), Savar, Dhaka.

Data collection and Statistical analysis: The Structure questionnaires was used to collect data. After completing collection of data, this data was cleaned, edited, entered into the computer and analysed by using descriptive statistics. Data was analysed by using Statistical Package for the Social Sciences (SPSS). The Chi square analysis was done to detect statistically significant association among variables.

\section{RESULTS}

Total 384 participants were included in this study. Majority of the participants (36\%) were in age group 2 to 4 years and only $18 \%$ were in 4 to 6 age group. Among all participants, $58 \%$ of the participants were male and $42 \%$ of the participants were female. See figure 1 . Among all participants, 32 percent of the participants mother was secondary completed, 29.9 percent was primary, $14.1 \%$ was SSC, $9.1 \%$ was HSC, $8.1 \%$ was illiterate and only $6.8 \%$ was graduate completed. $32 \%$ of the participants mother was secondary completed, $29.9 \%$ was primary, $14.1 \%$ was SSC, 9.1\% was HSC, 8.1 percent was illiterate and only $6.8 \%$ was graduate completed. $69 \%$ of participants came from rural area and $31 \%$ of the participants were from urban area. The majority (48\%) of the participant's economic status were between the group BDT 6000 to 10000 .

\section{Medical information of participants-}

Among all $81 \%$ of the participants had visual problem and $19 \%$ of the participants had no history of visual problem. $89 \%$ of the participants had no hearing problem and only $11 \%$ of the participants had hearing problem. The majority (69\%) of the participants had no history of convulsion and only $31 \%$ of the participants had history of convulsion.
Motor type and topographical classification of the participants -The $79.2 \%$ of the participants were by spastic $\mathrm{CP}, 12.5 \%$ were athetoid, $5.7 \%$ were flaccid and $2.6 \%$ were ataxic $C P$. The majority (51\%) of the participants were diagnosed by spastic quadriplegic CP, 20.3\% were diplegic, $10.4 \%$ were hemiplegic, $7.6 \%$ were triplegic, $1.6 \%$ were monoplegic $\mathrm{CP}$ and $9.1 \%$ were in others. See figure 3 and 4.

\section{Developmental milestone of the participants-} Among all participants, 55\% participants had sitting ability and $45 \%$ of the participants had no sitting ability in this study. The $48 \%$ participants had crawling ability and $52 \%$ had no crawling ability in this study. The $19 \%$ participants had walking ability and most of the participants $(81 \%)$ had no walking ability in this study. See figure 5.

Distribution and association of age, gender, type and topographical classification of CP with GMFCS level: Among all participants, majority of participants were in level II. Only 31 numbers were level I. The researcher found that there were significant association between age in all age band ( $<2$ years, 2 to $4 y, 4$ to $6 y$ and 6 to 12 year) with the level of GMFCS. See table 1 . Amongst 384 participants 224 were male and 160 were female. Males were more common in all levels rather than female. Most frequent levels were level II, III, IV and V except I. There was no statistically significant association between gender with age group according to GMFCS ( $p$ value $=0.717$ ) that was more than 0.05 . See table 2. But the researcher did not find any significant association between type of CP and level of GMFCS ( $p$ value is more than 0.05). There were statistically significant association between topographical classification and age banned based on GMFCS at below 2 year, 2 to 4 year, 6 to 12 year ( $p$ value $=0.000$ ) and $p$ value $=0.030$ in 4 to 6-year age band.

Table 1: Distribution and association of participants age in relation to GMFCS.

\begin{tabular}{|c|c|c|c|c|c|c|c|}
\hline \multirow{2}{*}{ Age } & \multicolumn{5}{|c|}{ GMFCS } & \multirow{2}{*}{ Total } & \multirow{2}{*}{ Chi Square } \\
\hline & Level I & Level II & Level III & Level IV & Level V & & \\
\hline$<2 y$ & $3(0.8 \%)$ & 25 (6.5\%) & 11 (2.9\%) & $25(6.5 \%)$ & 39 (10.2\%) & 103 & \multirow{5}{*}{$p=0.000$} \\
\hline 2 to $4 y$ & 11 (2.9\%) & 36 (9.4\%) & $30(7.8 \%)$ & $31(8.1 \%)$ & $24(6.2 \%)$ & 132 & \\
\hline 4 to $6 y$ & $4(1 \%)$ & 19 (4.9\%) & 21 (5.5\%) & $16(4.2 \%)$ & $8(2.1 \%)$ & 68 & \\
\hline 6 to $12 y$ & $13(3.4 \%)$ & 23 (6\%) & 23 (6\%) & $17(4.4 \%)$ & 5 (1.3\%) & 81 & \\
\hline Total & 31 & 103 & 85 & 89 & 76 & 384 & \\
\hline
\end{tabular}


Table 2: Association between gender with GMFCS.

\begin{tabular}{|c|c|c|c|c|c|c|c|}
\hline \multirow{2}{*}{ Gender } & \multicolumn{5}{|c|}{ GMFCS } & \multirow{2}{*}{ Total } & \multirow{2}{*}{ Chi Square } \\
\cline { 2 - 7 } & Level I & Level II & Level III & Level IV & Level V & & \\
\hline Male & 18 & 53 & 52 & 51 & 50 & 224 & \multirow{2}{*}{$\begin{array}{c}\text { value } \\
>0.05\end{array}$} \\
\hline Female & 13 & 50 & 33 & 38 & 26 & 160 & \\
\hline Total & 31 & 103 & 85 & 89 & 76 & 384 & \\
\hline
\end{tabular}

Fig. 1: GMFCS expanded and revised for children aged 6 to 12 years.

\section{GMFCS E \& $R$ between $6^{\text {th }}$ and $12^{\text {th }}$ birthday: Descriptors and illustrations}

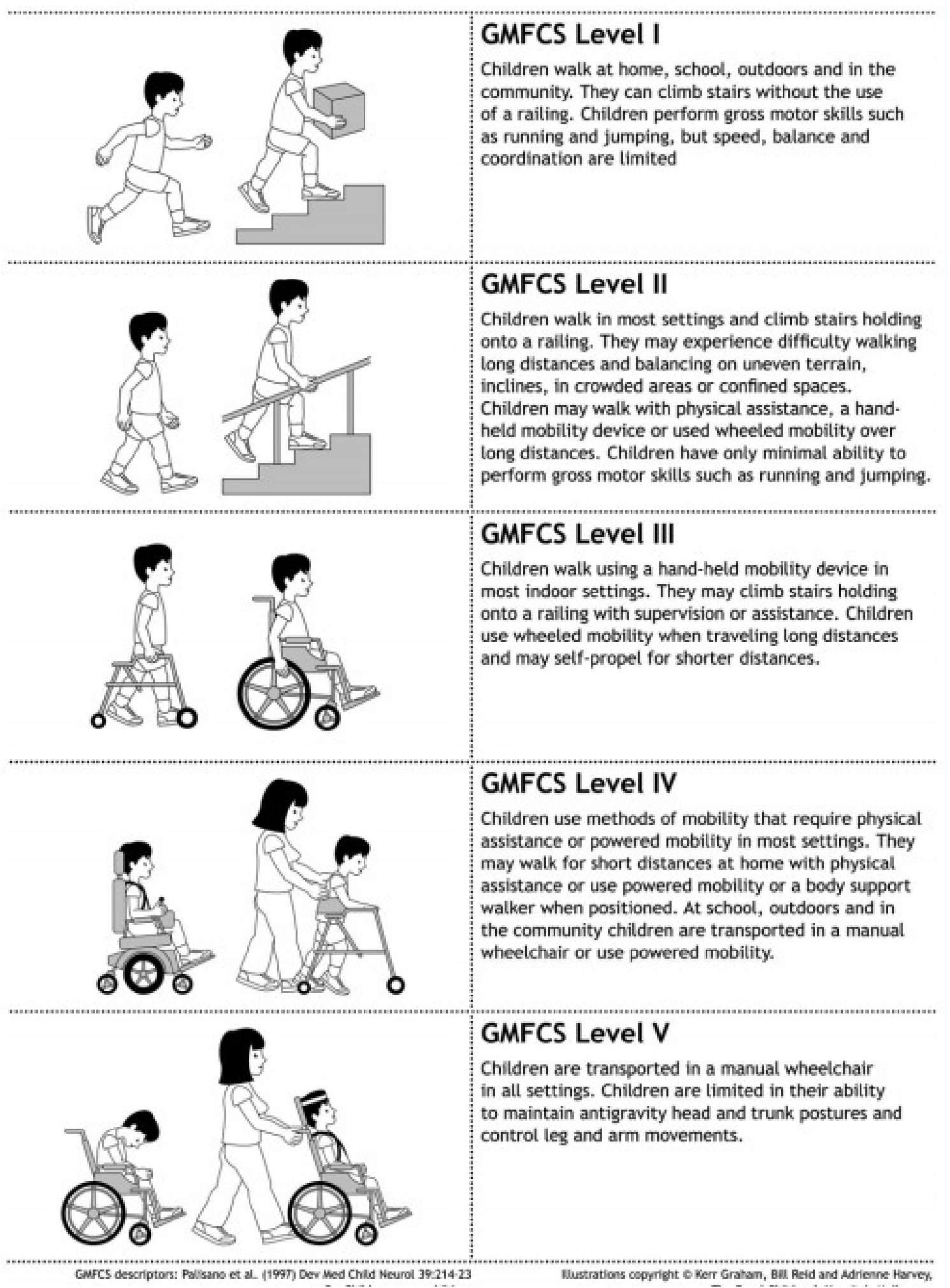


Fig. 2: Distribution of gender among participants.

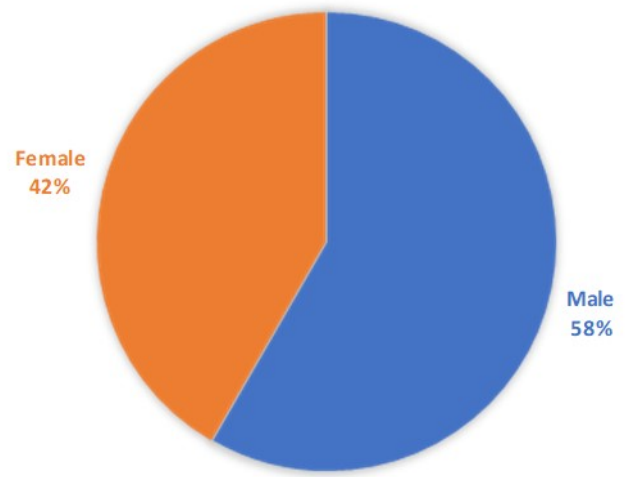

Fig. 3: Distribution of motor type of the participants $(n=384)$.

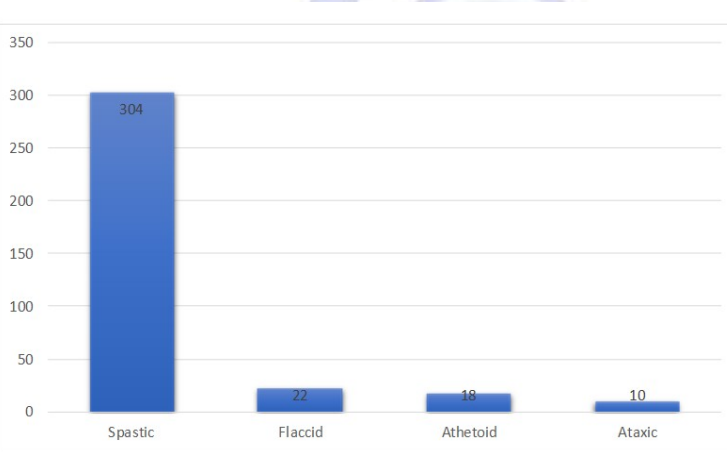

Fig. 4: Distribution of limb involvement/topographic classification among all participants.

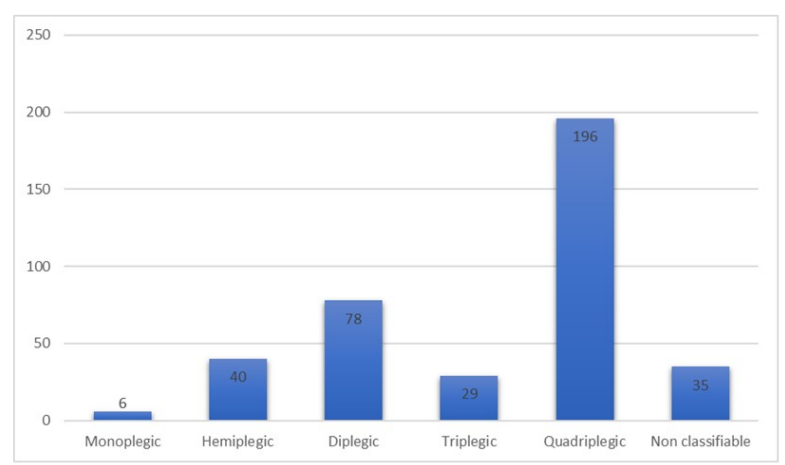

Fig. 5: Distribution of developmental milestone of the participants.

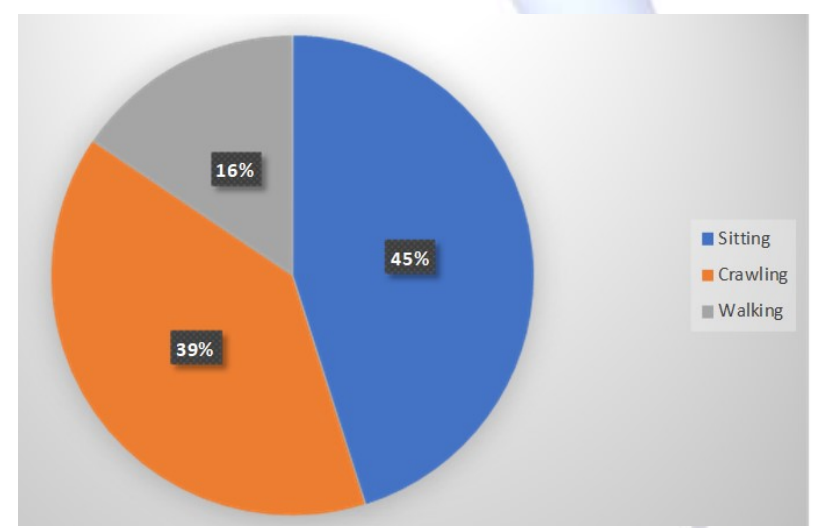

\section{DISCUSSION}

Gross Motor Function Classification System (GMFCS) has been widely used in clinical practice and in research which is considered valid, reliable and stable for 2 to 12 year- old children [8].

In this present study, majority of participants were in age group 2 to 4 years (36\%) and males (58\%) were affected by CP than female. The literature also found that males are more affected than females [9].

Majority of participants came from rural area. In associate impairments, $81 \%$ had visual problem and few participants (31\%) had convulsion. Developmental delay is a common feature in CP. In this study $55 \%$ had sitting and $48 \%$ had crawling ability. Only $19 \%$ participants had walking ability.

This study found spastic type of CP was more common and majority were quadriplegic and diplegic CP. The spastic type of CP is common than other type and consistent from many years [10]. In the distribution in body involvement, quadriplegic $\mathrm{CP}$ is more frequent in nationally and internationally [11]. But another study investigated that diplegic CP is more common [12].

The researcher found statistically significant association between age with GMFCS level $(p<0.05)$ but did not find any association between gender with GMFCS ( $p>0.05)$. The type of CP was not associated ( $p>0.05$ ) with GMFCS but topographical classification was associated the GMFCS $(p<0.05)$. But another study did not find the association between age, gender and motor type with motor level $(p=0.075)[6]$.

The Gross Motor Function System classification has been widely used to help therapeutic planning that consider the functional level of the child. This system focused the patients' ambulatory ffunction, use of mobility device and performance in sitting, standing and walking activities.

Limitation: Due to study of clinical based in one setting, the findings of the study will not be generalized for whole country. Researcher has done sample size calculation. The researcher used convenient sampling to collect data.

\section{CONCLUSION}

Gross motor function classification system helps to establish a rehabilitation goal for each level in different age group. This classification 
system is associated with age, type of cerebral palsy and topographical distribution in children with cerebral palsy.

\section{ACKNOWLEDGEMENTS}

We would like to thanks all participants who were participated in this study.

\section{Conflicts of interest: None}

\section{REFERENCES}

[1]. Hagberg B, Hagberg G, Beckung E, Uvebrant P. Changing panorama of cerebral palsy in Sweden. VIII. Prevalence and origin in the birth year period 199194. Acta Paediatrica. 2001 Mar;90(3):271-7.

[2]. Bax M, Goldstein M, Rosenbaum P, Leviton A, Paneth N, Dan B, Jacobsson B, Damiano D. Proposed definition and classification of cerebral palsy, April 2005. Developmental medicine and child neurology. 2005 Aug;47(8):571-6.

[3]. Hanna SE, Bartlett DJ, Rivard LM, Russell DJ. Reference curves for the Gross Motor Function Measure: percentiles for clinical description and tracking over time among children with cerebral palsy. Physical therapy. 2008 May 1;88(5):596-607.

[4]. Palisano R, Rosenbaum P, Walter S, Russell D, Wood E, Galuppi B. Development and reliability of a system to classify gross motor function in children with cerebral palsy. Developmental Medicine \& Child Neurology. 1997 Apr;39(4):214-23.

[5]. Beckung E, Hagberg G. Neuroimpairments, activity limitations, and participation restrictions in children with cerebral palsy. Developmental medicine and child neurology. 2002 May;44(5):309-16.

[6]. Pfeifer LI, Silva DB, Funayama CA, Santos JL. Classification of cerebral palsy: association between gender, age, motor type, topography and Gross Motor Function. Arquivos de neuro-psiquiatria. 2009 Dec;67(4):1057-61.
[7]. Morris C, Bartlett D. Gross motor function classification system: impact and utility. Developmental medicine and child neurology. 2004 Jan;46(1):60-5.

[8]. Wood E, Rosenbaum P. The gross motor function classification system for cerebral palsy: a study of reliability and stability over time. Developmental medicine and child neurology. 2000 May;42(5): 292-6.

[9]. Romeo DM, Cioni M, Scoto M, Mazzone L, Palermo F, Romeo MG. Neuromotor development in infants with cerebral palsy investigated by the Hammersmith Infant Neurological Examination during the first year of age. European Journal of Paediatric Neurology. 2008 Jan 1;12(1):24-31.

[10]. Beckung E, Carlsson G, Carlsdotter S, Uvebrant P. The natural history of gross motor development in children with cerebral palsy aged 1 to 15 years. Developmental Medicine \& Child Neurology. 2007 Oct 1;49(10):751-6.

[11]. Howard J, Soo B, Graham HK, Boyd RN, Reid S, Lanigan A, Wolfe R, Reddihough DS. Cerebral palsy in Victoria: motor types, topography and gross motor function. Journal of paediatrics and child health. 2005 Sep;41(9 10):479-83.

[12].Voorman JM, Dallmeijer AJ, Knol DL, Lankhorst GJ, Becher JG. Prospective longitudinal study of gross motor function in children with cerebral palsy. Archives of physical medicine and rehabilitation. 2007 Jul 1;88(7):871-6.

$$
\begin{aligned}
& \text { How to cite this article: } \\
& \text { Mst. Rabea Begum, Mohammad Anwar Hossain, Shahnaj Sultana. GROSS } \\
& \text { MOTOR FUNCTION CLASSIFICATION SYSTEM (GMFCS) FOR CHILDREN WITH } \\
& \text { CEREBRAL PALSY. Int J Physiother Res 2019;7(6):3281-3286. DOI: 10.16965/ } \\
& \text { ijpr.2019.180 }
\end{aligned}
$$

